\title{
BMJ Open Prevalence and determinants of metabolic syndrome in Qatar: results from a National Health Survey
}

\author{
Mohamed Hamad Al-Thani, ${ }^{1}$ Al Anoud Mohammed Al-Thani, ${ }^{1}$ Sohaila Cheema, ${ }^{2}$ \\ Javaid Sheikh, ${ }^{3}$ Ravinder Mamtani, ${ }^{2}$ Albert B Lowenfels, ${ }^{4}$ \\ Walaa Fattah Al-Chetachi, ${ }^{1}$ Badria Ali Almalki, ${ }^{1}$ Shamseldin Ali Hassan Khalifa, ${ }^{1}$ \\ Ahmad Omar Haj Bakri, ${ }^{1}$ Patrick Maisonneuve ${ }^{5}$
}

To cite: Al-Thani MH, Al-Thani AAM, Cheema S, et al. Prevalence and determinants of metabolic syndrome in Qatar: results from a National Health Survey. BMJ Open 2016;6 e009514. doi:10.1136/ bmjopen-2015-009514

- Prepublication history and additional material is available. To view please visit the journal (http://dx.doi.org/ 10.1136/bmjopen-2015009514).

Received 24 July 2015

Revised 7 June 2016

Accepted 12 July 2016

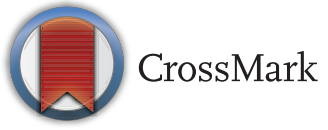

${ }^{1}$ Department of Public Health, Supreme Council of Health, Doha, Qatar

${ }^{2}$ Department of Global and Public Health, Weill Cornell Medical College, Doha, Qatar ${ }^{3}$ Office of the Dean, Weill Cornell Medical College, Doha, Qatar

${ }^{4}$ Department of Surgery and Department of Family Medicine, New York Medical College, Valhalla, New York, USA

${ }^{5}$ Division of Epidemiology and Biostatistics, European Institute of Oncology, Milan, Italy

Correspondence to Professor Ravinder Mamtani; ram2026@qatar-med.cornell. edu

\section{ABSTRACT}

Objectives: To determine optimum measurements for abdominal obesity and to assess the prevalence and determinants of metabolic syndrome in Qatar.

Design: National health survey.

Setting: Qatar National STEPwise Survey conducted by the Supreme Council of Health during 2012.

Participants: 2496 Qatari citizens aged 18-64 representative of the general population.

\section{Primary and secondary outcome measures:}

Measure of obesity (body mass index, waist circumference or waist-to-height ratio) that best identified the presence of at least 2 other factors of metabolic syndrome; cut-off values of waist circumference; frequency of metabolic syndrome.

Results: Waist circumference $\geq 102$ for men and $\geq 94 \mathrm{~cm}$ for women was the best predictor of the presence of other determinants of metabolic syndrome (raised blood pressure, fasting blood glucose, triglycerides and reduced high-density lipoprotein cholesterol). Using these values, we identified $28 \%$ of Qataris with metabolic syndrome, which is considerably lower than the estimate of $37 \%$ calculated using the International Diabetes Federation (IDF) criteria. Restricting the analysis to participants without known elevated blood pressure, elevated blood sugar or diabetes $16.5 \%$ would be classified as having metabolic syndrome. In a multivariable logistic regression analysis, the prevalence of metabolic syndrome increased steadily with age $(\mathrm{OR}=3.40(95 \%$ Cl 2.02 to 5.74), OR=5.66 (3.65 to 8.78), OR=10.2 (5.98 to 17.6) and $\mathrm{OR}=18.2$ (7.01 to 47.5) for those in the age group ' $30-39$ ', '40-49', '50-59', '60-64' vs '18-29'; $p<0.0001)$, decreased with increasing educational attainment $(\mathrm{OR}=0.61$ ( 0.39 to 0.96$)$ for those who attained 'secondary school or more' compared with 'less than primary school'; $p=0.03$ ) and exercise ( $\mathrm{OR}=0.60$ ( 0.42 to 0.86 ) for those exercising $\geq 3000$ vs $<600 \mathrm{MET}-\mathrm{min} /$ week; $p=0.006$ ) but was not associated with smoking or diet.

Conclusions: Waist circumference was the best measure of obesity to combine with other variables to construct a country-specific definition of metabolic syndrome in Qatar. Approximately $28 \%$ of adult Qatari citizens satisfy the criteria for metabolic syndrome,

\section{Strengths and limitations of this study}

- This is the first study to establish optimal cut-off values for waist circumference for Qataris, which is a crucial criterion for a realistic estimation of the prevalence of metabolic syndrome in this population.

- The study is based on a WHO STEPS survey, a well-established and tested method specifically for chronic non-communicable diseases (NCD) risk factor surveillance.

- As for any population survey, the assumption is made that the sample of individuals interviewed is representative of the whole population.

which increased significantly with age. Education and physical activity were inversely associated with this syndrome.

\section{INTRODUCTION}

Metabolic syndrome is a combination of individual risk factors that are associated with several serious health conditions such as diabetes, cardiovascular disease or stroke. It is diagnosed by the presence of three or more of five risk factors: abdominal obesity, raised blood pressure (BP), raised fasting blood glucose, raised triglycerides and reduced high-density lipoprotein (HDL) cholesterol. The prevalence of metabolic syndrome is therefore highly dependent on the cut-off points used for the definition of each single component of metabolic syndrome, and particularly for the definition of abdominal obesity. Abdominal obesity is normally measured by waist circumference and broad ethnic-group suboptimal cut-off points have been proposed. ${ }^{12}$ Until more specific data are available for Middle East countries, the International Diabetes Federation

(IDF) 
recommended using European cut-off points for all Eastern Mediterranean and Middle East (Arab) populations. ${ }^{1}$

The aims of this study were: first, to confirm results from a previous study ${ }^{3}$ showing that waist circumference was an appropriate measure of central obesity for the identification of metabolic syndrome among Qatari citizens; second, to assess optimal cut-off points for waist circumference in Qataris from data in a representative National Health Survey; third, to use these cut-off points to determine the prevalence and fourth, the determinants of metabolic syndrome among Qatari citizens.

\section{MATERIALS AND METHODS}

\section{Survey instrument and sampling}

Qatar had a total adult population of about 1.5 million inhabitants in 2010 comprising 240000 Qatari Nationals (39\% aged $<15,58 \%$ aged $15-64$ and $3 \%$ aged 65 or more). ${ }^{4}$

We obtained survey data from a random sample of 2496 adult Qatari citizens aged 18-64 that were collected during the year 2012 by the trained Qatar Supreme Council of Health staff based on the WHO's established method for estimating non-communicable diseases prevalence and risk factors, as part of surveillance.

The same standardised questions and protocols have been used in many WHO member countries for monitoring within-country trends and for making comparisons across countries. General details on the survey are available at the WHO website, ${ }^{5}$ and country-specific details are available in a report from the Supreme Council of Health, Qatar. ${ }^{6}$ Briefly, a two-stage sample design was used, selecting primary sampling units (PSUs) at the first stage and a sample of households within each selected PSU at the second stage. A total of 96 PSUs were selected from the Qatari frame of PSUs. In the second stage, 30 households were selected from each selected PSU by simple systematic sampling. Interviewers visited each selected household and identified all survey-eligible individuals. A personal digital assistant device was used to generate a random number to select one individual, either male or female, from within the household. Only these selected individuals were administered the questionnaire at their household. Since biomedical tests require 12 hours of fasting, appointments were given based on the agreement between the interviewers and the respondents and were conducted at the household level on Saturdays. In total 2496 of the 2850 Qatari households selected were interviewed, corresponding to an overall response rate of 88\%. An Arabic standardised version of the stepwise data collection form (Questionnaire) was used in the survey, gathering:

- Demographic and behavioural risk factors: age, sex, years at school, tobacco and smokeless tobacco use, types of physical activity, sedentary behaviour, fruit and vegetable consumption, history of raised BP, history of diabetes and oral health;
- Physical measurements: height and weight, waist circumference, hip circumference, BP;

- Blood samples for biochemical measurements: fasting blood glucose, total cholesterol, HDL cholesterol, LDL-cholesterol and triglycerides.

All the Qatar national STEPwise questionnaires were tested for cultural applicability and sensitivity through word and pilot testing of the questionnaires.

This research proposal had been previously reviewed and approved by the Qatar Supreme Council of Health. The Office of Research Integrity at Weill Cornell Medical College in Qatar reviewed the proposal for secondary research analysis of those data by the authors and determined that such secondary analysis was exempt from Qatari and American human subject protection regulations and therefore did not require review by an institutional review board.

\section{Definition of metabolic syndrome and physical activity assessment}

Metabolic syndrome was defined according to the IDF criteria. ${ }^{1}$ It combines several individual risk factors including raised fasting blood glucose $(\geq 100 \mathrm{mg} / \mathrm{dL}$ or taking diabetes medication), raised BP (systolic $\mathrm{BP} \geq 130 \mathrm{~mm} \mathrm{Hg}$ or diastolic $\mathrm{BP} \geq 85 \mathrm{~mm} \mathrm{Hg}$, or taking anti-hypertensive medication), raised triglycerides $(\geq 150 \mathrm{mg} / \mathrm{dL})$, reduced HDL cholesterol $(<40$ in men or $<50 \mathrm{mg} / \mathrm{dL}$ in women) and central obesity defined as waist circumference with ethnicity specific values (using Qatar-specific cut-offs estimated from this study: waist circumference $\geq 102$ in men or $\geq 94 \mathrm{~cm}$ in women or body mass index $(\mathrm{BMI}) \geq 30 \mathrm{~kg} / \mathrm{m}^{2}$ ). According to the IDF criteria, ${ }^{1}$ if BMI is $>30 \mathrm{~kg} / \mathrm{m}^{2}$, central obesity can be assumed and waist circumference does not need to be measured. If three or more of these risk factors are present, then metabolic syndrome is present. ${ }^{1}$

We calculated the total physical activity using the Global Physical Activity Questionnaire developed by the WHO. ${ }^{7}$ This instrument collects information on physical activity participation in three settings (activity at work, travel to and from places, recreational activities) and sedentary behaviour. Participants were categorised into low, moderate and high levels of activity based on the sum of their total metabolic equivalent (MET)-minutes of activity computed for each setting (1 MET being defined as $1 \mathrm{kcal} / \mathrm{kg} /$ hour and is equivalent to the energy cost of sitting quietly).

\section{Data analysis}

Demographic and health characteristics of the Qatari population were evaluated using data from a crosssectional WHO STEPwise survey conducted in 2012. The STEPS tool was designed to cover three levels of risk factor assessment: step 1-demographic and behavioural risk factors information, step 2-physical measurements in household settings and step 3-biochemical measurements. The data were weighted using population weights to adjust for age and sex differences 
between the sample and the national population. Percentages, means and corresponding 95\% CIs were then calculated using the weighted data. Comparison of percentages across groups of participants was assessed using the Rao-Scott $\chi^{2}$ test, which is a design-adjusted version of the Pearson $\chi^{2}$ test.

We evaluated the prevalence of each single component of metabolic syndrome in men and women by different age groups. We used the receiver operator characteristic (ROC) curve analysis to assess the performance of various measures of obesity (BMI, waist circumference, waist-to-height ratio) for the identification of those with at least two other components of metabolic syndrome and calculated the area under the curve (AUC) (or 'c-statistic') to assess the prediction ability of each parameter. Optimal waist circumference cut-off points that maximise total accuracy (sensitivity and specificity) were calculated by the intersection of the plots of sensitivity and specificity separately for men and for women and combined with other measurements to assess the prevalence of metabolic syndrome in Qatar.

Finally, we searched for lifestyle factors associated with metabolic syndrome using logistic regression, adjusting models for potential confounders such as age, gender or educational attainment level. When present, missing data were treated as a separate category and represented by dummy variables, allowing logistic regression models to be fitted on the whole population.

Data analysis was performed using the SURVEYFREQ SURVEYMEANS, SURVEYREG and SURVEYLOGISTIC procedures of the SAS software (V.9.2, Cary, North Carolina, USA). All tests were two-sided and $\mathrm{p}$ values $<0.05$ considered statistically significant.

\section{RESULTS}

The survey sample consisted of 1053 male and 1443 female Qataris. Table 1 contains sociodemographic characteristics of participants according to gender. Significant gender-related differences were observed for educational attainment, with significantly more women (14.6\%) than men $(5.4 \%)$ who had attained less than primary school, for marital status with more women than men being divorced or widowed $(6.4 \%$ and $3.9 \%$, respectively, for women and $2.2 \%$ and $0.2 \%$ for men) and for occupation with the majority of men $(64.7 \%)$ being government employees, while homemakers were the largest group in women $(38.8 \%)(\mathrm{p}<0.0001)$. The age distribution $(\mathrm{p}=0.21)$ was similar in men and women.

\section{Best obesity measure that predicts metabolic syndrome}

We performed ROC curve analysis to determine which obesity measure (BMI, waist circumference or waist-to-height ratio) and the corresponding cut-off points that best predict metabolic syndrome. For this analysis, we plotted the sensitivity versus 1-specificity for all possible values of the three obesity measures to predict the presence of at least two of the four remaining factors of metabolic syndrome (raised BP, raised fasting blood glucose, raised triglycerides or reduced

Table 1 Sociodemographic characteristics of participants according to gender

\begin{tabular}{|c|c|c|c|c|}
\hline Demographic information & Total $(n=2496), \%$ & Men $(n=1053), \%$ & Women ( $n=1443), \%$ & $\begin{array}{l}\text { Rao-Scott } \\
\chi^{2} \text { ( } p \text { value) }\end{array}$ \\
\hline & 100 & 100 & 100 & \\
\hline Age group (years) & & & & 0.21 \\
\hline $18-29$ & 40.1 & 39.6 & 40.6 & \\
\hline 30-39 & 25.7 & 27.5 & 24.0 & \\
\hline $40-49$ & 19.5 & 17.8 & 21.1 & \\
\hline $50-59$ & 11.1 & 11.0 & 11.2 & \\
\hline $60-64$ & 3.6 & 4.1 & 3.1 & \\
\hline Educational attainment & & & & $<0.0001$ \\
\hline Secondary school or more & 67.0 & 67.4 & 66.7 & \\
\hline Primary/preparatory school & 22.8 & 27.1 & 18.7 & \\
\hline Less than primary school & 10.1 & 5.4 & 14.6 & \\
\hline Marital status & & & & $<0.0001$ \\
\hline Never married & 29.8 & 30.1 & 29.5 & \\
\hline Currently married & 63.8 & 67.5 & 60.2 & \\
\hline Divorced & 4.3 & 2.2 & 6.4 & \\
\hline Widowed & 2.1 & 0.2 & 3.9 & \\
\hline Occupation & & & & $<0.0001$ \\
\hline Government employee & 49.1 & 64.7 & 34.0 & \\
\hline Non-government employee & 5.6 & 8.7 & 2.7 & \\
\hline Student & 13.4 & 11.3 & 15.5 & \\
\hline Homemaker & 19.9 & 0.5 & 38.8 & \\
\hline Retired & 7.5 & 8.8 & 6.3 & \\
\hline Other & 4.4 & 6.1 & 2.7 & \\
\hline
\end{tabular}


HDL cholesterol) (figure 1). Waist circumference and waist-to-height ratio were better predictors of metabolic syndrome than BMI in men and women, yielding respective moderate AUC of $0.612,0.620$ and 0.579 in men and $0.722,0.728$ and 0.685 in women. The classifier performance of waist circumference is, however, only poor in men and fair in women.

We therefore confirmed that waist circumference (criteria used by the IDF), which has similar predictive value of metabolic syndrome than waist-to-height ratio and necessitates a single measurement with no calculation, is an appropriate measure of central obesity. The waist circumference cut-off points that maximised total accuracy (sensitivity and specificity) were 102 for men and $94 \mathrm{~cm}$ for women, respectively. The corresponding sensitivity and specificity for the detection of metabolic syndrome were $57.8 \%$ and $58.4 \%$ in men and $65.7 \%$ and $66.7 \%$ in women.

\section{Waist circumference distribution}

We assessed the waist circumference of Qatari men and women and the proportion of those with measures above cut-off points defined by the IDF in the absence of ethnic-specific values ( $\geq 94$ for men and $\geq 80 \mathrm{~cm}$ for women), Adult Treatment Panel III (ATP-III) ( $\geq 102$ for men and $\geq 88 \mathrm{~cm}$ for women) or obtained from the previous ROC curves analysis for Qatari citizens ( $\geq 102$ for men and $\geq 94 \mathrm{~cm}$ for women) (table 2). Average waist circumference was $100 \mathrm{~cm}$ (95\% CI 98 to 102) for men and $90 \mathrm{~cm} \mathrm{(95 \%} \mathrm{CI} 88$ to 92) for women. Average waist circumference increased steadily with age in both sexes to reach $106 \mathrm{~cm}(95 \%$ CI 101 to 112) and $103 \mathrm{~cm} \mathrm{(95 \%}$ CI 98 to 108), respectively, for men and women aged
$60-64$. Using the cut-off points proposed by the IDF ( $\geq 94$ for men and $\geq 80 \mathrm{~cm}$ for women, ie, the same as those used for Europeans), $63.4 \%$ of men and $68.5 \%$ of women would be at risk, with the proportion as high as $77.1 \%$ in men and $92.4 \%$ in women aged 60 or more. Using the less-stringent ATP-III ${ }^{2}$ cut-off points $(\geq 102$ for men and $\geq 88 \mathrm{~cm}$ for women), the proportion of men and women with a waist circumference indicative of central obesity will diminish to $45.4 \%$ and $51.3 \%$, respectively (for all age groups). Using Qatar-specific cut-off points identified by ROC curve analysis ( $\geq 102$ for men and $\geq 94 \mathrm{~cm}$ for women), only $45.4 \%$ of men and $38.7 \%$ of women would be considered to have waist measurement indicative of central obesity.

\section{Prevalence of metabolic syndrome}

The prevalence of metabolic syndrome and its components is presented in table 3 , stratified by gender and age group. This information was collected at different steps of the survey and was available for a variable number of participants (1470 for fasting blood glucose, 2342 for BP, 1518 for triglycerides level, 1526 for HDL cholesterol and 2356 for abdominal obesity). As a result, information on metabolic syndrome was available for $1373(55 \%)$ participants.

Considering all age groups together, reduced HDL cholesterol (51.9\%) and abdominal obesity (50.7\%) were the most common single components of metabolic syndrome in men, while abdominal obesity (50.5\%) and raised BP $(43.3 \%)$ were the most common single components of metabolic syndrome in women.

Overall, the prevalence of metabolic syndrome in Qatar based on country-specific estimates of waist

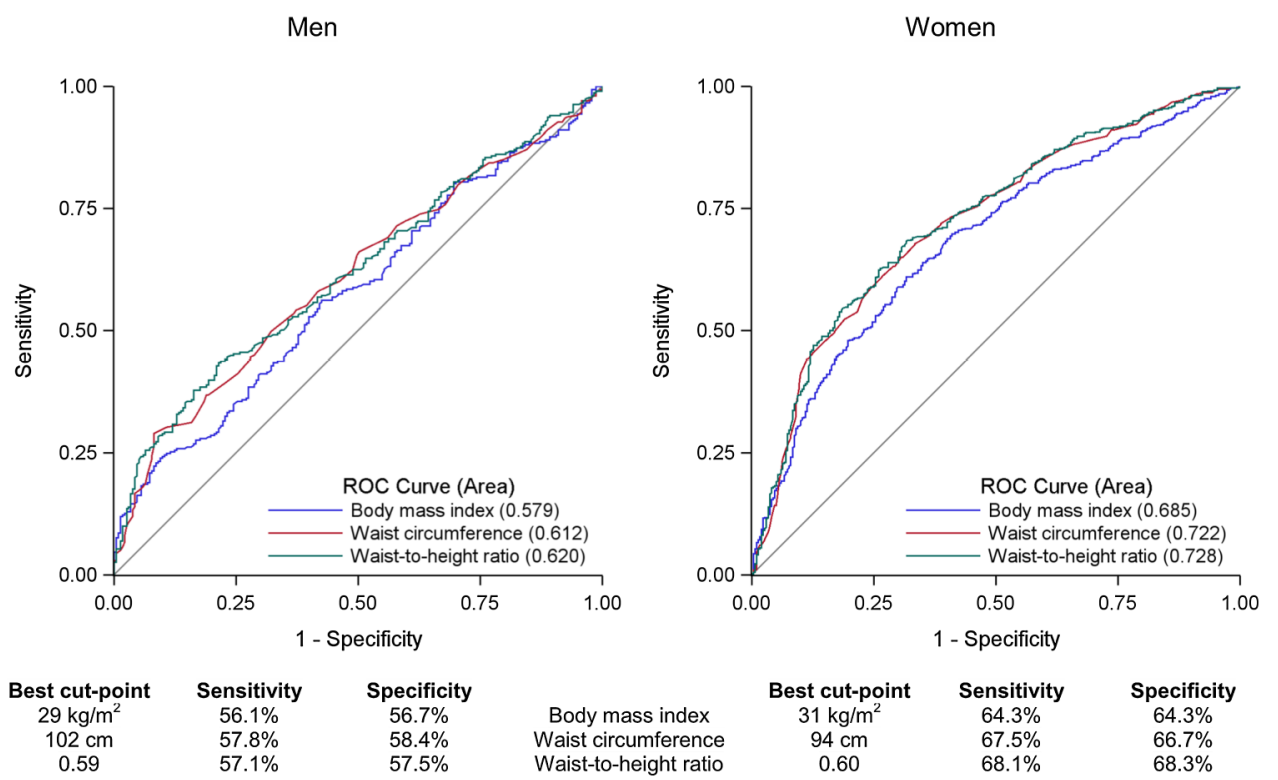

Figure 1 Receiver operator characteristic (ROC) curves for body mass index, waist circumference and waist-to-height ratio to predict the presence of at least two factors of metabolic syndrome (excluding abdominal obesity) in men and women in Qatar. Information on body mass index was available for 2384 participants, waist circumference for 2335 participants and waist-to-height ratio for 2333 participants. 


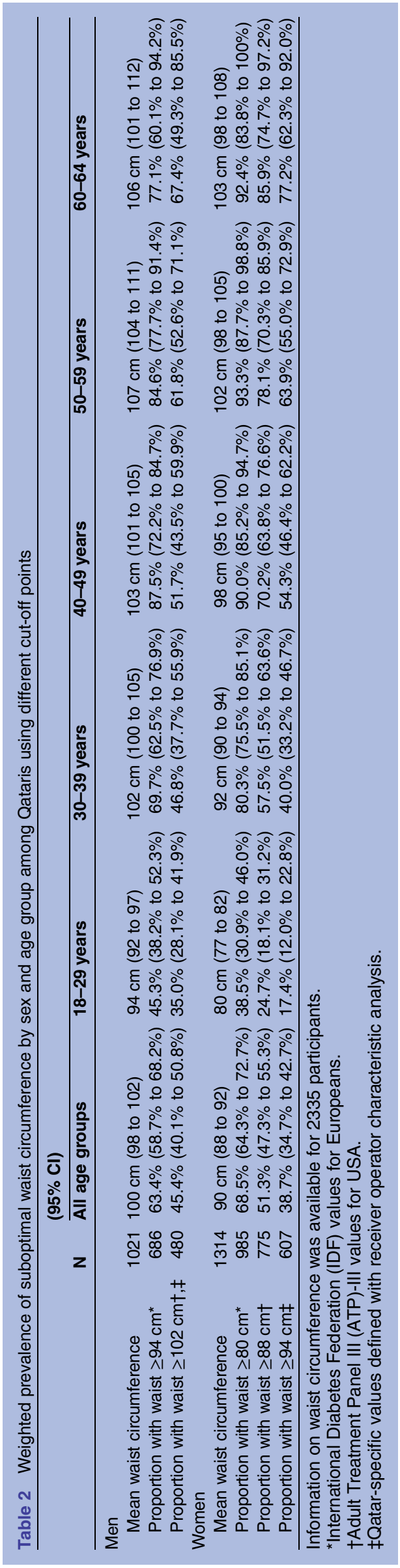

circumference was $27.7 \%$ (95\% CI $24.5 \%$ to $30.9 \%$ ) for both sexes combined, $28.7 \%$ (95\% CI $23.6 \%$ to $33.7 \%$ ) in men and $26.8 \%$ (95\% CI $23.1 \%$ to $30.4 \%$ ) in women. This prevalence increases with age from $9.3 \%(95 \% \mathrm{CI}$ $6.0 \%$ to $12.7 \%$ ) in those under the age of 30 to $70.2 \%$ (95\% CI $54.1 \%$ to $86.3 \%$ ) in those aged $60-64$.

\section{Determinants of metabolic syndrome}

We used multivariable logistic regression to identify sociodemographic or lifestyle factors associated with metabolic syndrome (table 4). After adjustment for age and educational attainment level, gender was not associated with the risk of metabolic syndrome. The risk of metabolic syndrome, however, significantly increased with increasing age with $\mathrm{OR}=3.40(95 \%$ CI 2.02 to 5.74$)$; $\mathrm{OR}=5.66$ (95\% CI 3.65 to 8.78$)$; OR=10.2 (95\% CI 5.98 to 17.6$)$ and $\mathrm{OR}=18.2(95 \%$ CI 7.01 to 47.5$)$ for those in the age group '30-39', '40-49', '50-59', '60-64' compared with those in the '18-29' age group $(\mathrm{p}<0.0001)$, but decreased with increasing educational attainment with $\mathrm{OR}=0.61 \quad(95 \%$ CI 0.39 to 0.96$)$ for those who attained 'secondary school or more' compared with 'less than primary school' $(p=0.03)$. No statistical significant association was observed for marital status or occupation. The particularly low but not statistically significant risk for students may be in part due to residual confounding from age, marital status and physical activity.

Neither tobacco smoking nor any single component of the diet recorded at the survey (see online supplementary table) was associated with metabolic syndrome. After adjustment for age, gender and educational attainment, the risk of metabolic syndrome was reduced by $40 \%$ for those with high physical activity levels (at least 3000 MET-min/week) compared with those with low physical activity level ( $<600 \mathrm{MET}-\mathrm{min} /$ week $) \quad(\mathrm{OR}=0.60$; $95 \%$ CI 0.42 to 0.86$)(\mathrm{p}=0.006)$.

\section{Metabolic syndrome among 'healthy' individuals}

The survey was conducted to be representative of the general population and therefore included a proportion of participants with previous diagnosis of diabetes or hypertension. Overall, $70 \%$ of the participants with available information about metabolic syndrome had never been previously told by a doctor or other health worker that they had either hypertension or diabetes. We reassessed the prevalence of metabolic syndrome and its components among these presumed 'healthy participants' (table 5). In this subset, the survey eventually found that $13.7 \%$ (95\% CI $10.1 \%$ to $17.2 \%$ ) had elevated fasting blood glucose, and $31.6 \%$ (95\% CI $28.8 \%$ to $34.4 \%$ ) had raised BP; metabolic syndrome was present in $16.5 \%$ (95\% CI $13.5 \%$ to $19.5 \%$ ).

\section{DISCUSSION}

Health professionals depend on estimates of the frequency of metabolic syndrome to plan effective strategies for controlling several serious conditions within a 
Table 3 Weighted prevalence of metabolic syndrome and its components by sex and age group among Qataris

\begin{tabular}{|c|c|c|c|c|c|c|c|}
\hline & \multirow[b]{2}{*}{$\begin{array}{l}\mathrm{N} \text { exposed/ } \\
\mathrm{N} \text { available }\end{array}$} & \multicolumn{6}{|l|}{$\%(95 \% \mathrm{Cl})$} \\
\hline & & All age groups & $18-29$ years & $30-39$ years & 40-49 years & $50-59$ years & $60-64$ years \\
\hline \multicolumn{8}{|l|}{ Both sexes $(n=2496)$} \\
\hline Metabolic syndrome ( $\geq 3$ risk factors) & $430 / 1373$ & $27.7 \%(24.5 \%$ to $30.9 \%)$ & $9.3 \%(6.0 \%$ to $12.7 \%)$ & $26.0 \%(19.8 \%$ to $32.3 \%)$ & $37.9 \%(32.2 \%$ to $43.6 \%)$ & $54.0 \%(45.2 \%$ to $62.7 \%)$ & $70.2 \%(54.1 \%$ to $86.3 \%)$ \\
\hline Raised fasting blood glucose $\dagger$ & $374 / 1470$ & $22.5 \%(19.0 \%$ to $26.0 \%)$ & $12.3 \%(7.9 \%$ to $16.8 \%)$ & $15.7 \%(9.6 \%$ to $21.9 \%)$ & $31.0 \%(24.7 \%$ to $37.4 \%)$ & $44.7 \%(35.8 \%$ to $53.7 \%)$ & $55.0 \%(40.3 \%$ to $69.7 \%)$ \\
\hline Raised BP $\ddagger$ & $1107 / 2432$ & $42.7 \%(40.0 \%$ to $45.4 \%)$ & $28.2 \%(23.7 \%$ to $32.6 \%)$ & $36.2 \%$ ( $31.6 \%$ to $40.9 \%)$ & $54.9 \%(50.2 \%$ to $59.6 \%)$ & $73.9 \%(68.0 \%$ to $79.8 \%)$ & $87.5 \%(78.4 \%$ to $96.7 \%)$ \\
\hline Raised triglycerides§ & $270 / 1518$ & $16.4 \%(13.7 \%$ to $19.0 \%)$ & $9.0 \%(5.7 \%$ to $12.3 \%)$ & $18.1 \%(12.7 \%$ to $23.5 \%)$ & $20.6 \%(15.9 \%$ to $25.2 \%)$ & $26.5 \%(18.0 \%$ to $35.0 \%)$ & $24.2 \%(12.7 \%$ to $35.8 \%)$ \\
\hline Reduced HDL cholesterol & $676 / 1526$ & $45.5 \%(41.3 \%$ to $49.8 \%)$ & $38.4 \%(31.7 \%$ to $45.1 \%)$ & $48.1 \%(40.8 \%$ to $55.3 \%)$ & $49.1 \%(42.4 \%$ to $55.7 \%)$ & $51.7 \%(43.7 \%$ to $59.7 \%)$ & $62.3 \%(47.6 \%$ to $77.0 \%)$ \\
\hline Abdominal obesity** & $1302 / 2356$ & $50.6 \%(47.7 \%$ to $53.6 \%)$ & $33.0 \%(28.1 \%$ to $37.9 \%)$ & $54.2 \%(49.0 \%$ to $59.5 \%)$ & $64.4 \%(59.7 \%$ to $69.2 \%)$ & $68.9 \%(62.7 \%$ to $75.1 \%)$ & $75.6 \%(64.0 \%$ to $87.3 \%)$ \\
\hline \multicolumn{8}{|l|}{ Men $(n=1053)$} \\
\hline Metabolic syndrome ( $\geq 3$ risk factors) & $179 / 538$ & $28.7 \%(23.6 \%$ to $33.7 \%)$ & $9.5 \%(4.4 \%$ to $14.6 \%)$ & $26.4 \%(17.8 \%$ to $34.9 \%)$ & $38.5 \%(30.2 \%$ to $46.9 \%)$ & $62.3 \%(50.0 \%$ to $74.5 \%)$ & $66.6 \%(42.0 \%$ to $91.2 \%)$ \\
\hline Raised fasting blood glucose $†$ & $152 / 552$ & $23.1 \%(17.6 \%$ to $28.6 \%)$ & $11.4 \%(6.0 \%$ to $16.9 \%)$ & $13.6 \%(5.2 \%$ to $21.9 \%)$ & $34.6 \%(24.3 \%$ to $44.9 \%)$ & $50.8 \%(36.7 \%$ to $64.9 \%)$ & $55.5 \%(32.3 \%$ to $78.6 \%)$ \\
\hline Raised BP $\ddagger$ & $470 / 1022$ & $42.1 \%(38.5 \%$ to $45.6 \%)$ & $25.8 \%(20.0 \%$ to $31.7 \%)$ & $35.1 \%(28.3 \%$ to $41.9 \%)$ & $54.5 \%(47.5 \%$ to $61.5 \%)$ & $80.1 \%(73.2 \%$ to $86.9 \%)$ & $86.9 \%(74.8 \%$ to $99.0 \%)$ \\
\hline Raised triglycerides§ & $110 / 573$ & $17.2 \%(13.0 \%$ to $21.3 \%)$ & $6.5 \%(1.5 \%$ to $11.4 \%)$ & $21.2 \%(12.7 \%$ to $29.7 \%)$ & $20.4 \%(13.6 \%$ to $27.3 \%)$ & $33.3 \%(19.2 \%$ to $47.3 \%)$ & $25.4 \%(9.4 \%$ to $41.5 \%)$ \\
\hline Reduced HDL cholesterol & $290 / 575$ & $51.9 \%(45.2 \%$ to $58.6 \%)$ & $45.8 \%(34.9 \%$ to $56.7 \%)$ & $53.8 \%(41.1 \%$ to $66.5 \%)$ & $54.6 \%(45.8 \%$ to $63.5 \%)$ & $56.7 \%(45.9 \%$ to $67.4 \%)$ & $65.0 \%(43.6 \%$ to $86.3 \%)$ \\
\hline Abdominal obesity** & $541 / 1031$ & $50.7 \%(46.0 \%$ to $55.5 \%)$ & $38.6 \%(31.2 \%$ to $46.0 \%)$ & $54.9 \%(46.7 \%$ to $63.1 \%)$ & $58.7 \%(50.9 \%$ to $66.5 \%)$ & $64.2 \%(55.1 \%$ to $73.3 \%)$ & $68.1 \%(50.1 \%$ to $86.0 \%)$ \\
\hline \multicolumn{8}{|l|}{ Women $(n=1443)$} \\
\hline Metabolic syndrome ( $\geq 3$ risk factors) & $251 / 835$ & $26.8 \%(23.1 \%$ to $30.4 \%)$ & $9.1 \%(4.2 \%$ to $14.0 \%)$ & $25.6 \%(17.7 \%$ to $33.5 \%)$ & $37.3 \%(28.6 \%$ to $46.0 \%)$ & $46.7 \%$ (37.2\% to $56.2 \%)$ & $75.8 \%(59.0 \%$ to $92.6 \%)$ \\
\hline Raised fasting blood glucose $\dagger$ & 222/918 & $21.9 \%(17.7 \%$ to $26.1 \%)$ & $13.1 \%(7.1 \%$ to $19.2 \%)$ & $18.2 \%(10.6 \%$ to $25.8 \%)$ & $27.9 \%(20.3 \%$ to $35.6 \%)$ & $39.5 \%(26.9 \%$ to $52.0 \%)$ & $54.2 \%$ (34.5\% to $74.0 \%)$ \\
\hline Raised BP $\ddagger$ & $637 / 1410$ & $43.3 \%(38.9 \%$ to $47.6 \%)$ & $30.3 \%(23.5 \%$ to $37.2 \%)$ & $37.4 \%(30.3 \%$ to $44.4 \%)$ & $55.2 \%(48.3 \%$ to $62.0 \%)$ & $67.9 \%(60.5 \%$ to $75.3 \%)$ & $88.3 \%(79.3 \%$ to $97.4 \%)$ \\
\hline Raised triglycerides§ & $160 / 945$ & $15.6 \%(12.6 \%$ to $18.6 \%)$ & $11.2 \%(6.2 \%$ to $16.2 \%)$ & $14.6 \%(8.8 \%$ to $20.4 \%)$ & $20.7 \%(14.8 \%$ to $26.5 \%)$ & $20.8 \%(13.2 \%$ to $28.3 \%)$ & $22.3 \%(6.3 \%$ to $38.2 \%)$ \\
\hline Reduced HDL cholesterol & $386 / 951$ & $39.4 \%$ (34.6\% to $44.2 \%)$ & $31.7 \%(24.4 \%$ to $39.0 \%)$ & $41.5 \%$ (33.4\% to $49.6 \%)$ & $44.1 \%(35.3 \%$ to $52.9 \%)$ & $47.4 \%(36.9 \%$ to $58.0 \%)$ & $58.0 \%$ (37.7\% to $78.3 \%)$ \\
\hline Abdominal obesity ${ }^{\star \star}$ & $761 / 1325$ & $50.5 \%(47.1 \%$ to $53.9 \%)$ & $26.9 \%(20.9 \%$ to $33.0 \%)$ & $53.5 \%(46.9 \%$ to $60.0 \%)$ & $69.2 \%(63.6 \%$ to $74.8 \%)$ & $73.6 \%(65.5 \%$ to $81.6 \%)$ & $85.1 \%(73.7 \%$ to $96.5 \%)$ \\
\hline \multicolumn{8}{|c|}{ 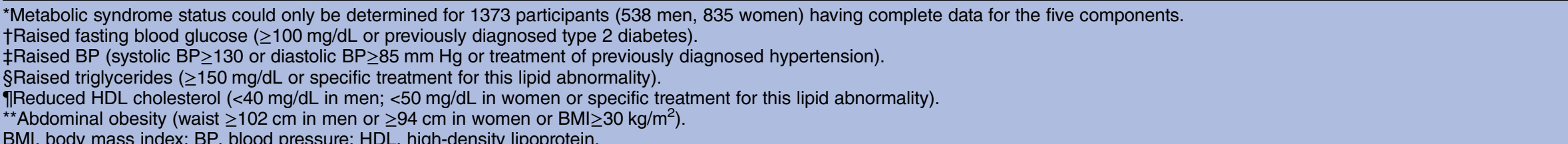 } \\
\hline
\end{tabular}


Table 4 Characteristics associated with metabolic syndrome at multivariable analysis

\begin{tabular}{|c|c|c|c|}
\hline Characteristics* & Total & $\begin{array}{l}\text { Percentage of participants } \\
\text { with metabolic syndrome }\end{array}$ & OR (95\% Cl)† \\
\hline All & 1373 & 27.7 & \\
\hline \multicolumn{4}{|l|}{ Gender } \\
\hline Men & 538 & 28.7 & 1.00 \\
\hline Women & 835 & 26.8 & 0.83 (0.62 to 1.12$)$ \\
\hline \multicolumn{4}{|l|}{ Age group (years) } \\
\hline $18-29$ & 337 & 9.3 & 1.00 \\
\hline 30-39 & 353 & 26.0 & 3.40 (2.02 to 5.74$)$ \\
\hline $40-49$ & 396 & 37.9 & 5.66 (3.65 to 8.78$)$ \\
\hline $50-59$ & 214 & 54.0 & 10.25 (5.98 to 17.6$)$ \\
\hline $60-64$ & 73 & 70.2 & $18.24(7.01$ to 47.5$)$ \\
\hline \multicolumn{4}{|l|}{ Education } \\
\hline Less than primary school & 169 & 50.0 & 1.00 \\
\hline Primary/preparatory school & 312 & 30.3 & $0.70(0.39$ to 1.26$)$ \\
\hline Secondary school or more & 891 & 23.3 & 0.61 (0.39 to 0.96$)$ \\
\hline \multicolumn{4}{|l|}{ Marital status } \\
\hline Never married & 263 & 10.3 & 1.00 \\
\hline Currently married & 979 & 33.2 & $1.40(0.67$ to 2.94$)$ \\
\hline Divorced & 81 & 41.8 & 1.97 (0.87 to 4.43$)$ \\
\hline Widowed & 50 & 52.5 & $1.73(0.51$ to 5.90$)$ \\
\hline \multicolumn{4}{|l|}{ Occupation } \\
\hline Government employee & 631 & 24.2 & 1.00 \\
\hline Non-government employee & 64 & 23.7 & 1.07 (0.40 to 2.83$)$ \\
\hline Student & 117 & 4.3 & $0.38(0.14$ to 1.06$)$ \\
\hline Homemaker & 354 & 37.6 & 1.56 (0.94 to 2.59$)$ \\
\hline Retired & 157 & 53.6 & 1.53 (0.94 to 2.49$)$ \\
\hline \multicolumn{4}{|l|}{ Tobacco smoking } \\
\hline Never smoked tobacco & 1126 & 28.1 & 1.00 \\
\hline Ever smoked tobacco & 247 & 26.5 & $0.76(0.47$ to 1.23$)$ \\
\hline Currently smoke tobacco & 195 & 23.7 & 0.72 (0.47 to 1.12$)$ \\
\hline Currently smoke daily tobacco & 177 & 23.4 & 0.71 (0.45 to 1.12$)$ \\
\hline \multicolumn{4}{|l|}{ Physical activity } \\
\hline Low (<600 MET-min/week) & 643 & 31.9 & 1.00 \\
\hline Average (600-3000 MET-min/week) & 304 & 29.3 & $0.90(0.64$ to 1.28$)$ \\
\hline High $(\geq 3000$ MET-min/week) & 398 & 20.4 & 0.60 (0.42 to 0.86$)$ \\
\hline
\end{tabular}

given population. Thus, it is extremely important that the estimated prevalence of metabolic syndrome be reliable and based on information that is appropriate for the selected region or country.

The major organisations concerned with defining metabolic syndrome recognise that central adiposity-an important component of this syndrome-is most easily measured by waist circumference. ${ }^{1}{ }^{2}$ Furthermore, the IDF has emphasised the need for determining countryspecific estimates of cut-off points for waist circumference in calculating the prevalence of metabolic syndrome. In fact, there is good evidence that body composition varies among ethnic groups, Asians having lower cut-off points than Europeans, and AfricanAmericans and Hispanics having similar cut-off points to Europeans. Differences between populations could relate to genetic differences that may affect body composition, environmental exposure and particularly nutritional differences such as early childhood nutrition exposures. ${ }^{8} \mathrm{~A}$ number of region-specific or population-specific estimates have been published, but there are only a few for Middle East countries and none for Qatar (table 6).

In previous publications, Bener et $a \hat{l}^{3}{ }^{9}$ suggested that previous criteria for estimating the risk of metabolic syndrome as recommended by the WHO, the IDF and ATP-III might be inappropriate for Qatar. In particular, he and his coauthors proposed BMI, waist-to-hip and waist-to-height ratio in alternative to waist circumference as a measure of central obesity. ${ }^{3}$ We used data from the 2012 Qatar National STEPwise Survey to calculate the current prevalence of metabolic syndrome in Qatar. We confirmed that waist circumference was an appropriate parameter for identifying other individual components of metabolic syndrome. For the entire Qatari adult 


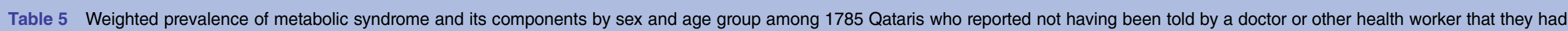
raised BP (or hypertension) or raised blood sugar (or diabetes)

\begin{tabular}{|c|c|c|c|c|c|c|}
\hline & \multirow{2}{*}{$\begin{array}{l}\mathrm{N} \text { exposed/ } \\
\mathrm{N} \text { available }\end{array}$} & \multicolumn{5}{|l|}{$\%(95 \% \mathrm{Cl})$} \\
\hline & & All age groups & $18-29$ years & $30-39$ years & $40-49$ years & $50-59$ years \\
\hline \multicolumn{7}{|l|}{ Both sexes $(n=1785)$} \\
\hline Metabolic syndrome ( $\geq 3$ risk factors) ${ }^{*}$ & $177 / 963$ & $16.5 \%(13.5 \%$ to $19.5 \%)$ & $5.5 \%(2.6 \%$ to $8.4 \%)$ & $22.0 \%(15.5 \%$ to $28.4 \%)$ & $25.9 \%(19.5 \%$ to $32.3 \%)$ & $31.3 \%(19.1 \%$ to $43.4 \%)$ \\
\hline Raised fasting blood glucose $\dagger$ & 151/1042 & $13.7 \%(10.1 \%$ to $17.2 \%)$ & $9.8 \%(5.4 \%$ to $14.3 \%)$ & $13.6 \%(7.3 \%$ to $19.8 \%)$ & $19.5 \%(13.7 \%$ to $25.3 \%)$ & $20.8 \%(11.6 \%$ to $30.0 \%)$ \\
\hline Raised BP $\ddagger$ & $568 / 1733$ & $31.6 \%(28.8 \%$ to $34.4 \%)$ & $24.0 \%(19.9 \%$ to $28.1 \%)$ & $31.5 \%(26.2 \%$ to $36.8 \%)$ & $45.0 \%(39.2 \%$ to $50.8 \%)$ & $48.2 \%(37.7 \%$ to $58.7 \%)$ \\
\hline Raised triglycerides§ & $147 / 1077$ & $12.4 \%(9.9 \%$ to $14.8 \%)$ & $7.9 \%(4.6 \%$ to $11.2 \%)$ & $15.6 \%(10.5 \%$ to $20.7 \%)$ & $15.3 \%(10.4 \%$ to $20.3 \%)$ & $19.8 \%(8.3 \%$ to $31.3 \%)$ \\
\hline Reduced HDL cholesterolף & $441 / 1083$ & $42.9 \%(38.1 \%$ to $47.8 \%)$ & $38.3 \%$ (30.9\% to $45.8 \%)$ & $46.5 \%(38.5 \%$ to $54.5 \%)$ & $47.9 \%(39.4 \%$ to $56.4 \%)$ & $40.5 \%(29.1 \%$ to $51.9 \%)$ \\
\hline Abdominal obesity** & $783 / 1666$ & $43.8 \%(40.2 \%$ to $47.4 \%)$ & $31.2 \%(25.8 \%$ to $36.6 \%)$ & $51.2 \%(44.8 \%$ to $57.6 \%)$ & $57.1 \%(51.1 \%$ to $63.1 \%)$ & $61.4 \%(52.2 \%$ to $70.6 \%)$ \\
\hline \multicolumn{7}{|l|}{ Men $(n=765)$} \\
\hline Metabolic syndrome ( $\geq 3$ risk factors) ${ }^{*}$ & $81 / 390$ & $17.6 \%(13.1 \%$ to $22.1 \%)$ & $5.0 \%(1.1 \%$ to $8.8 \%)$ & $24.1 \%(15.1 \%$ to $33.0 \%)$ & $28.3 \%(19.0 \%$ to $37.6 \%)$ & $34.3 \%(16.1 \%$ to $52.5 \%)$ \\
\hline Raised fasting blood glucose $\dagger$ & $59 / 399$ & $13.0 \%(7.9 \%$ to $18.1 \%)$ & $7.4 \%(2.9 \%$ to $11.8 \%)$ & $12.4 \%(3.7 \%$ to $21.1 \%)$ & $22.9 \%(12.9 \%$ to $32.9 \%)$ & $25.1 \%(9.3 \%$ to $40.9 \%)$ \\
\hline Raised BP $\ddagger$ & $243 / 741$ & $30.3 \%(26.4 \%$ to $34.2 \%)$ & $21.4 \%(15.4 \%$ to $27.4 \%)$ & $30.7 \%(23.2 \%$ to $38.2 \%)$ & $44.5 \%(36.1 \%$ to $52.9 \%)$ & $51.5 \%(37.7 \%$ to $65.3 \%)$ \\
\hline Raised triglycerides§ & $62 / 415$ & $13.4 \%(9.2 \%$ to $17.7 \%)$ & $6.3 \%(1.0 \%$ to $11.6 \%)$ & $18.2 \%(9.7 \%$ to $26.7 \%)$ & $18.7 \%(11.4 \%$ to $26.0 \%)$ & $25.6 \%(5.5 \%$ to $45.7 \%)$ \\
\hline Reduced HDL cholesterolๆ & $195 / 416$ & $49.3 \%(41.1 \%$ to $57.4 \%)$ & $44.7 \%$ (33.0\% to $56.4 \%)$ & $52.6 \%(39.1 \%$ to $66.1 \%)$ & $53.0 \%(41.8 \%$ to $64.2 \%)$ & $47.8 \%(28.5 \%$ to $67.1 \%)$ \\
\hline Abdominal obesity** & $351 / 750$ & $46.1 \%(40.6 \%$ to $51.6 \%)$ & $38.2 \%$ (30.4\% to $46.0 \%)$ & $52.2 \%(43.3 \%$ to $61.2 \%)$ & $53.9 \%(44.2 \%$ to $63.7 \%)$ & $50.9 \%(36.4 \%$ to $65.3 \%)$ \\
\hline \multicolumn{7}{|l|}{ Women $(n=1020)$} \\
\hline Metabolic syndrome ( $\geq 3$ risk factors) ${ }^{*}$ & $96 / 573$ & $15.3 \%(11.8 \%$ to $18.8 \%)$ & $6.0 \%(2.1 \%$ to $10.0 \%)$ & $19.0 \%(11.3 \%$ to $26.7 \%)$ & $23.5 \%(14.8 \%$ to $32.3 \%)$ & $29.2 \%(15.1 \%$ to $43.3 \%)$ \\
\hline Raised fasting blood glucose $\dagger$ & $92 / 643$ & $14.3 \%(10.0 \%$ to $18.6 \%)$ & $12.0 \%(5.5 \%$ to $18.5 \%)$ & $15.1 \%(8.1 \%$ to $22.0 \%)$ & $16.2 \%(9.6 \%$ to $22.8 \%)$ & $17.9 \%(5.9 \%$ to $29.9 \%)$ \\
\hline Raised BP $\ddagger$ & $325 / 992$ & $32.9 \%(28.5 \%$ to $37.3 \%)$ & $26.5 \%(20.2 \%$ to $32.7 \%)$ & $32.4 \%$ (25.4\% to $39.4 \%)$ & $45.4 \%$ (37.6\% to $53.3 \%)$ & $45.8 \%$ (32.7\% to $59.0 \%)$ \\
\hline Raised triglycerides§ & $85 / 662$ & $11.3 \%(8.2 \%$ to $14.3 \%)$ & $9.4 \%(4.7 \%$ to $14.1 \%)$ & $12.4 \%(7.4 \%$ to $17.4 \%)$ & $12.1 \%(6.6 \%$ to $17.7 \%)$ & $15.5 \%(4.2 \%$ to $26.8 \%)$ \\
\hline Reduced HDL cholesterolף & $246 / 667$ & $36.4 \%$ (30.9\% to $41.9 \%)$ & $32.5 \%(24.4 \%$ to $40.5 \%)$ & $38.9 \%(30.1 \%$ to $47.6 \%)$ & $43.0 \%(32.2 \%$ to $53.9 \%)$ & $35.0 \%(20.9 \%$ to $49.2 \%)$ \\
\hline Abdominal obesity ${ }^{\star *}$ & $432 / 916$ & $41.3 \%$ (37.6\% to $45.1 \%)$ & $23.4 \%(17.1 \%$ to $29.7 \%)$ & $49.8 \%(43.0 \%$ to $56.6 \%)$ & $60.0 \%(52.6 \%$ to $67.3 \%)$ & $69.0 \%(56.2 \%$ to $82.0 \%)$ \\
\hline \multicolumn{7}{|c|}{ 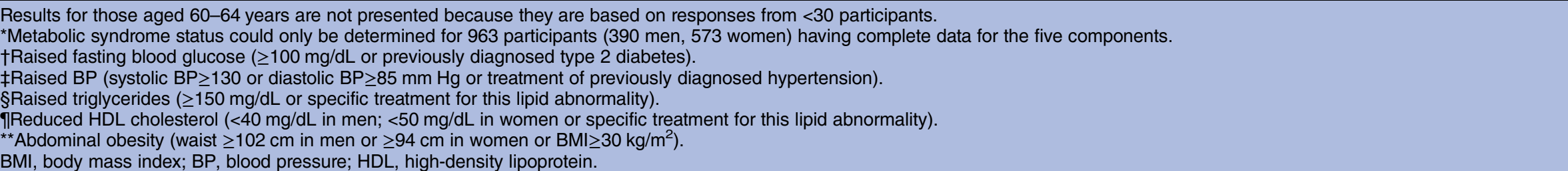 } \\
\hline
\end{tabular}


Table 6 Ethnic specific values for waist circumference from selected Middle East countries

\begin{tabular}{|c|c|c|c|}
\hline \multirow{2}{*}{$\begin{array}{l}\text { Region/ } \\
\text { population }\end{array}$} & \multicolumn{2}{|c|}{$\begin{array}{l}\text { Ethnic specific } \\
\text { values for waist } \\
\text { circumference } \\
\text { (cm) }\end{array}$} & \multirow[b]{2}{*}{ Reference } \\
\hline & Men & Women & \\
\hline Iran & 89 & 91 & Delavari et al ${ }^{11}$ \\
\hline Iran & 94.5 & 94.5 & Hadaegh et al ${ }^{12}$ \\
\hline Iran & 92.6 & 97.8 & Talaei et al ${ }^{13}$ \\
\hline Iran & 92 & 95 & Mirmiran et $a l^{14}$ \\
\hline Iran & 94.5 & - & Gharipour et $a l^{15}$ \\
\hline Iran & 91.5 & 85.5 & Esteghamati et $a l^{16}$ \\
\hline Iran, Kerman & 89 & 86 & Gozashti et al $1^{17}$ \\
\hline Iraq & 97 & 99 & Mansour et al ${ }^{18}$ \\
\hline Jordan & 97.8 & 95.6 & Al-Odat et al ${ }^{19}$ \\
\hline Omani Arabs & 80 & 84.5 & Al-Lawati et alpo \\
\hline Omani Arabs & 78.5 & 84.5 & Al-Lawati et alp1 \\
\hline Egypt & 93.5 & 91.5 & Ibrahim et $a^{22}$ \\
\hline Qatar & 102 & 94 & Current study \\
\hline
\end{tabular}

population, using the best cut-off points for waist circumference, we estimate the prevalence of metabolic syndrome in adults to be $28 \%$. This value resembles the previous overall estimate of $26 \%$ for this country obtained using the ATP-III criteria but considerably lower than the estimate of $37 \%$ derived from using the IDF criteria. $^{9}$ For comparison, estimates of the age-standardised prevalence of metabolic syndrome in the USA are $23 \%$. $^{10}$

In a multivariable analysis, the risk of metabolic syndrome increased steadily with age: participants aged 6064 were 18 times more likely to suffer from metabolic syndrome than those who were in the 18-30 age group. The frequency of metabolic syndrome was 39\% lower among participants with the highest level of educational attainment than in the group with the least amount of education. Exercise of at least 3000 MET-min/week lowered the risk of metabolic syndrome by $40 \%$ compared with persons in the lowest exercise group. Neither diet nor smoking had any impact on the occurrence of metabolic syndrome in this survey. This could be due to the fact that only basic information was collected on diet and because smoking prevalence is relatively low in Qatar. This analysis, however, suggests that among the various lifestyle factors that might alter the prevalence of metabolic syndrome in Qatar, exercise is the most important and deserves emphasis in any disease prevention programme.

Of interest, about $70 \%$ of participants in the sample survey were unaware of pre-existing diabetes or hypertension. After evaluation, $16.5 \%$ in this group were eventually diagnosed with metabolic syndrome.

The availability of specific waist circumference cut-off points for Qataris will also allow a better identification of the metabolic syndrome at the individual level in this population. Using lower cut-off points for Europeans, which are recommended in the absence of ethnicity specific data, would markedly increase the number of individuals classified at risk of Mets.

The strength of this study is that the data came from a carefully selected random population sample and data collection followed well-defined WHO criteria. As in other surveys, there was a different response rate for each step, especially for the collection of biological material. Fifty-five per cent of participants in the Qatar National STEPwise Survey provided a blood sample, which is still a fair response rate. Many individuals who live in this region refuse to provide blood samples for a variety of cultural reasons in survey situations such as this one, but we have no reason to believe that the blood sugar values of study participants who provided blood samples are different from the values of those who did not. However, this might introduce an unknown bias into the estimate of the prevalence of metabolic syndrome. We also recognised that treating missing data as a category in the regression models, as any other method to handle missing data, such as dropping subjects or imputation, could again have introduced some bias.

Another study limitation pertains to the accuracy of self-reported dietary information. This information is an estimate, which may not be a true measure of past or present food consumption. This could lead to inappropriate conclusions that the diet has no significant impact on prevention of metabolic syndrome. Finally, as for any population survey, the assumption was made that the sample of individuals interviewed is representative of the whole population. Our careful sampling framework should guarantee this assumption.

In summary, using new ethnic-specific cut-off points ( $\geq 102$ for men and $\geq 94 \mathrm{~cm}$ for women) derived from the ROC curve analysis of abdominal waist circumference, the prevalence of metabolic syndrome in adult Qataris is $28 \%$. We believe the new cut-off points for waist measurement from this country could be suitable for estimating the prevalence of metabolic syndrome in similar populations from other Middle East countries where country-specific data for waist measurements are unavailable.

Acknowledgements The authors would like to acknowledge the Supreme Council of Health staff for data collection.

Contributors All the authors have made substantive intellectual contributions to this study: MHA-T, AAMA-T, SC, JS, RM, ABL and PM designed the study. WFA-C, BAA, SAHK and AOHB conducted the study and collected the data. $\mathrm{PM}$ analysed the data. PM and $\mathrm{ABL}$ drafted the manuscript. RM, SC, JS and AAMA-T edited the manuscript. All the authors reviewed the manuscript and approved the final version.

Funding This work was funded by both the Supreme Council of Health and Qatar Foundation through the Weill Cornell Medical College in Qatar Biomedical Research Program.

Competing interests None declared.

Ethics approval Qatar Supreme Council of Health.

Provenance and peer review Not commissioned; externally peer reviewed. 
Data sharing statement Data are from the Qatar National STEPwise Survey whose authors may be contacted at the Supreme Council of Health, Qatar (AAMA-T; Manager Health Promotion and Noncommunicable Diseases, email: aalthani@sch.gov.qa).

Open Access This is an Open Access article distributed in accordance with the Creative Commons Attribution Non Commercial (CC BY-NC 4.0) license, which permits others to distribute, remix, adapt, build upon this work noncommercially, and license their derivative works on different terms, provided the original work is properly cited and the use is non-commercial. See: http:// creativecommons.org/licenses/by-nc/4.0/

\section{REFERENCES}

1. Alberti KG, Eckel RH, Grundy SM, et al. International Diabetes Federation Task Force on Epidemiology and Prevention; National Heart, Lung, and Blood Institute; American Heart Association; World Heart Federation; et al. Harmonizing the metabolic syndrome: a joint interim statement of the International Diabetes Federation Task Force on Epidemiology and Prevention; National Heart, Lung, and Blood Institute; American Heart Association; World Heart Federation; International Atherosclerosis Society; and International Association for the Study of Obesity. Circulation 2009;120:1640-5.

2. National Cholesterol Education Program (NCEP) Expert Panel on Detection, Evaluation, and Treatment of High Blood Cholesterol in Adults (Adult Treatment Panel III). Third Report of the National Cholesterol Education Program (NCEP) Expert Panel on Detection, Evaluation, and Treatment of High Blood Cholesterol in Adults (Adult Treatment Panel III) final report. Circulation 2002;106:3143-421.

3. Bener A, Yousafzai MT, Darwish S, et al. Obesity index that better predict metabolic syndrome: body mass index, waist circumference, waist hip ratio, or waist height ratio. J Obes 2013;2013:269038.

4. Doha: Qatar Statistics Authority. Vital Statistics Annual (Births and Deaths 2009) 2010;26: http://www.qix.gov.qa/portal/page/portal/ QIXPOC/Documents/QIX Knowledge Base/Publication/Population Statistics/Vital/Source_QSA/Births_Deaths_Foetal_Deaths_QSA_ AnBu_AE 2009.pdf (accessed 29 Aug 2016).

5. STEPwise approach to surveillance (STEPS). http://www.who.int/ chp/steps/en/ (accessed 09 Oct 2015).

6. Haj Bakri A, Al-Thani A. Chronic disease risk factor surveillance: Qatar STEPS report 2012. Qatar: The Supreme Council of Health, 2013. http://www.qsa.gov.qa/eng/publication/STEPWISE-Report/ STEPwise_Report.pdf (accessed on 21 Jul 2015).

7. Global Physical Activity Questionnaire (GPAQ) Questionnaire or physical activity surveillance. http://www.who.int/chp/steps/GPAQ/en/ (accessed on 21 Jul 2015).

8. Lear SA, James PT, Ko GT, et al. Appropriateness of waist circumference and waist-to-hip ratio cutoffs for different ethnic groups. Eur J Clin Nutr 2010;64:42-61.
9. Bener A, Zirie M, Musallam M, et al. Prevalence of metabolic syndrome according to Adult Treatment Panel III and International Diabetes Federation criteria: a population-based study. Metab Syndr Relat Disord 2009;7:221-9.

10. Beltrán-Sánchez $\mathrm{H}$, Harhay MO, Harhay MM, et al. Prevalence and trends of metabolic syndrome in the adult U.S. population, 19992010. J Am Coll Cardiol 2013;62:697-703.

11. Delavari A, Forouzanfar MH, Alikhani S, et al. First nationwide study of the prevalence of the metabolic syndrome and optimal cutoff points of waist circumference in the Middle East: the National survey of risk factors for noncommunicable diseases of Iran. Diabetes Care 2009;32:1092-7.

12. Hadaegh F, Zabetian A, Sarbakhsh $\mathrm{P}$, et al. Appropriate cutoff values of anthropometric variables to predict cardiovascular outcomes: 7.6 years follow-up in an Iranian population. Int $J$ Obes (Lond) 2009;33:1437-45

13. Talaei M, Thomas GN, Marshall T, et al. Appropriate cut-off values of waist circumference to predict cardiovascular outcomes: 7-year follow-up in an Iranian population. Intern Med 2012;51:139-46.

14. Mirmiran P, Esmaillzadeh A, Azizi F. Detection of cardiovascular risk factors by anthropometric measures in Tehranian adults: receiver operating characteristic (ROC) curve analysis. Eur J Clin Nutr 2004;58:1110-18.

15. Gharipour M, Sadeghi M, Dianatkhah M, et al. The cut-off values of anthropometric indices for identifying subjects at risk for metabolic syndrome in Iranian elderly men. J Obes 2014;2014:907149.

16. Esteghamati $\mathrm{A}$, Ashraf $\mathrm{H}$, Rashidi $\mathrm{A}$, et al. Waist circumference cut-off points for the diagnosis of metabolic syndrome in Iranian adults. Diabetes Res Clin Pract 2008;82:104-7.

17. Gozashti MH, Najmeasadat F, Mohadeseh S, et al. Determination of most suitable cut off point of waist circumference for diagnosis of metabolic syndrome in Kerman. Diabetes Metab Syndr 2014;8:8-12.

18. Mansour AA, Al-Hassan AA, Al-Jazairi MI. Cut-off values for waist circumference in rural Iraqi adults for the diagnosis of metabolic syndrome. Rural Remote Health 2007;7:765.

19. Al-Odat AZ, Ahmad MN, Haddad FH. References of anthropometric indices of central obesity and metabolic syndrome in Jordanian men and women. Diabetes Metab Syndr 2012;6:15-21.

20. Al-Lawati JA, Barakat NM, Al-Lawati AM, et al. Optimal cut-points for body mass index, waist circumference and waist-to-hip ratio using the Framingham coronary heart disease risk score in an Arab population of the Middle East. Diab Vasc Dis Res 2008:5:304-9.

21. Al-Lawati JA, Jousilahti P. Body mass index, waist circumference and waist-to-hip ratio cut-off points for categorisation of obesity among Omani Arabs. Public Health Nutr 2008:11:102-8.

22. Ibrahim MM, Elamragy AA, Girgis $\mathrm{H}$, et al. Cut off values of waist circumference and associated cardiovascular risk in Egyptians. BMC Cardiovasc Disord 2011;11:53. 